\title{
Contact Loss beneath Track Slab Caused by Deteriorated Cement Emulsified Asphalt Mortar: Dynamic Characteristics of Vehicle-Slab Track System and Prototype Experiment
}

\author{
Dan Liu, ${ }^{1,2}$ Yu-feng Liu, ${ }^{3}$ Juan-juan Ren, ${ }^{1,2}$ Rong-shan Yang, ${ }^{1,2}$ and Xue-yi Liu ${ }^{1,2}$ \\ ${ }^{1}$ MOE Key Laboratory of High-Speed Railway Engineering, Southwest Jiaotong University, Chengdu 610031, China \\ ${ }^{2}$ School of Civil Engineering, Southwest Jiaotong University, Chengdu 610031, China \\ ${ }^{3}$ The Charles E. Via, Jr. Department of Civil \& Environmental Engineering, Virginia Polytechnic Institute and State University, \\ Blacksburg, VA 24061, USA
}

Correspondence should be addressed to Xue-yi Liu; xyliu@home.swjtu.edu.cn

Received 27 June 2016; Revised 26 September 2016; Accepted 19 October 2016

Academic Editor: Yuri Vladimirovich Mikhlin

Copyright (C) 2016 Dan Liu et al. This is an open access article distributed under the Creative Commons Attribution License, which permits unrestricted use, distribution, and reproduction in any medium, provided the original work is properly cited.

\begin{abstract}
The contact loss beneath track slab caused by deteriorated cement emulsified asphalt mortar (CA mortar) has been one of the main diseases occurring in the CRTS- (China Railway Track System-) I Slab Track of high-speed railway in China. Based on the slab track design theory and the vehicle-track coupling vibration theory, a vehicle-track vertical coupling dynamic FEM model was established to analyze the influence of the contact loss length on the dynamic characteristics of vehicle and track subsystems at different train speeds. A prototype dynamic characteristic experimental test of CRTS-I Slab Track with CA mortar contact loss was conducted to verify the FEM model results. The train load was generated by the customized ZSS50 excitation car. The results showed that when the operation speed is less than $300 \mathrm{~km} / \mathrm{h}$, the contact loss with length smaller than $2.0 \mathrm{~m}$ barely affects the running smoothness ride safety of vehicle. The contact loss length effect on the dynamic characteristics of track subsystem is pronounced, especially on the track slab. Once the contact loss beneath the track slab occurs, the vibration displacement and the acceleration of the track slab increase rapidly, while it has little influence on the displacement and acceleration of the concrete roadbed.
\end{abstract}

\section{Introduction}

Nonballasted track, which is smoother and more stable and requires lower maintenance, has been proven to be the best track structure type for high-speed railway $[1,2]$. CRTSI Slab Track, which is technically improved from Japanese Shinkansen Slab track, is one of the main nonballasted track types used in Chinese high-speed railways and has been widely applied on Chinese passenger dedicated lines (PDLs), whose total mileage has exceeded $2200 \mathrm{~km}$.

Due to the coupling action of train load, temperature load, and environmental conditions, the CRTS-I slab track inevitably generates various types of diseases. Cement emulsified asphalt mortar (CA mortar), which is one of the main components of CRTS-I slab track, plays an important role in maintaining the elasticity of structure and makes the maintenance more convenient [3-5]. During the construction process, the CA mortar of CRTS-I slab track is poured into the bag between track slab and concrete roadbed [6], which leads to the poor connections between CA mortar and track slab and between CA mortar and concrete roadbed. Therefore, the interface between track slab and CA mortar becomes a vulnerable position of CRTS-I Slab Track. Based on field investigations, the contact loss beneath track slabs caused by deteriorated CA mortar is the main common disease of CRTS-I Slab Track $[7,8]$. It may change the path of force transfer, which will affect the mechanical behavior of structure [9]. Therefore, it is important to investigate the influence of contact loss beneath track slabs on the dynamic characteristic of slab track.

Some researchers have studied the impact of CA mortar contact loss beneath track slabs on the dynamic characteristic of slab track. Shi [10] analyzed the effect of slab track defect on the dynamic performances of slab track. The results showed 


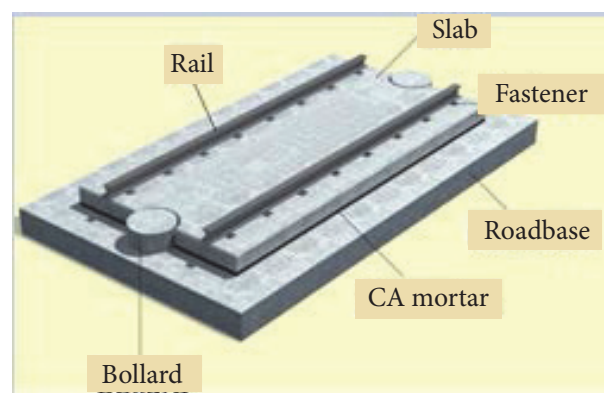

(a) Schematic diagram of CRTS-I Slab Track

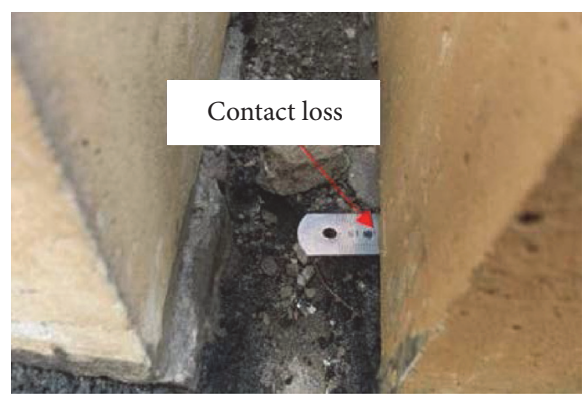

(b) Site picture of CRTS-I Slab Track with contact loss

FIGURE 1: CRTS-I Slab Track.

that the deterioration of CA mortar has great impact on the slab track, leading to the great increase of the acceleration of slab track. Xiang et al. [11] found that the contact loss caused by the deterioration of CA mortar would lead to the increase of the acceleration and displacement of track slabs. Li et al. [12] studied the influence of contact loss on the dynamic characteristics of the unit slab track on bridge. The results showed that the contact loss of CA mortar has significant influence on the vibration performance of the track. Previous researches have mainly focused on the FEM dynamic simulation, but experimental verification lacks. In this paper, a FEM model was applied to analyze the influence of contact loss beneath track slabs on the mechanical performance of slab track and the operation performance of vehicles with different train speeds, and an experimental testing of the dynamic characteristic of CRTS-I track slab with contact loss was conducted to verify the FEM results.

\section{The Mechanism and Characteristics of Contact Loss}

CRTS-I Slab Track (as shown in Figure 1(a)) consists of unit prefabricated slabs measuring $4.95 \mathrm{~m} \times 2.40 \mathrm{~m} \times 0.19 \mathrm{~m}$, CA mortar adjustment layer measuring $4.95 \mathrm{~m} \times 2.4 \mathrm{~m} \times$ $0.05 \mathrm{~m}$, reinforced concrete roadbed measuring $5.0 \mathrm{~m} \times 3.2 \mathrm{~m}$ $\times 0.3 \mathrm{~m}$, cylindrical bollards, and resin filled around bollards. It has the same structure on the subgrade and bridge and in tunnel.

The fresh CA mortar is consisting of cement, emulsified asphalt, sand, water, and admixtures (such as aluminum powder and superplasticizer) [13]. Unlike cement or asphalt, CA mortar has unique properties combining the strength of cement and the flexibility of asphalt [14]. The mechanical properties of CA mortar (such as strength, elasticity, and damping) play an important role in ride smoothness and ride safety.

During the construction process, because the CA mortar is poured by means of its own gravity, its filling is likely to be uncompacted. It is one of the main causes of contact loss beneath track slabs. On the other hand, CA mortar is very sensitive with environmental conditions like water and temperature. The coupling effect of high frequency train load, temperature, and environmental conditions degrades the CA mortar strength and causes the deterioration of CA mortar performance. The contact loss beneath track slab caused by the deteriorated CA mortar may change the mechanical behavior of structure and affect the ride smoothness and safety.

According to field researches, the contact loss beneath track slabs can occur at the corner, the end (as shown in Figure 1(b)), and the middle. Based on the research conducted by Yang et al. [15], the structure with CA mortar damage located at the adjacent slab end is under the worst working condition. In this study, the lateral contact loss (with height of $5 \mathrm{~mm}$ and width of $2.4 \mathrm{~m}$ ) beneath the end of track slab was taken into consideration.

\section{Vehicle-Track Vertical Coupled Vibration FEM Model}

3.1. Vehicle-Track Vertical Coupled Dynamic Model. Because of the complexity of structure and the coupling of vehicletrack system [16-18], it is very complicated and timeconsuming to accurately describe the in-service conditions of vehicle subsystem and track subsystem. Therefore, the vehicle-track system needs to be simplified. In order to analyze the influence of contact loss beneath track slabs on the dynamic characteristics of vehicle and track subsystems, based on the vehicle-track coupling vibration theory, a 3D simplified vehicle-track vertical coupled vibration model was established by using LS-DYNA (see Figure 2).

(1) This model included a vehicle subsystem and a track subsystem. The vehicle subsystem was considered as a multirigid-body system which consists of a car body, two bogies and four wheel-sets [19]. The wheel-set and bogie were connected by primary suspensions, and the bogie and car body were connected by secondary suspensions. Both primary suspensions and secondary suspensions were simplified as spring/damper systems. The main parameters for the vehicle subsystem are listed in Table 1.

(2) The track subsystem was simplified as continuous elastic discrete support beam-shell FEM model [20, 21]. In the track subsystem, rail was supported by a series of discrete spring/damper elements which acted as fasteners [22]; track slab and concrete roadbed were both modeled as shell which was supported in a continuous manner; CA mortar under the 


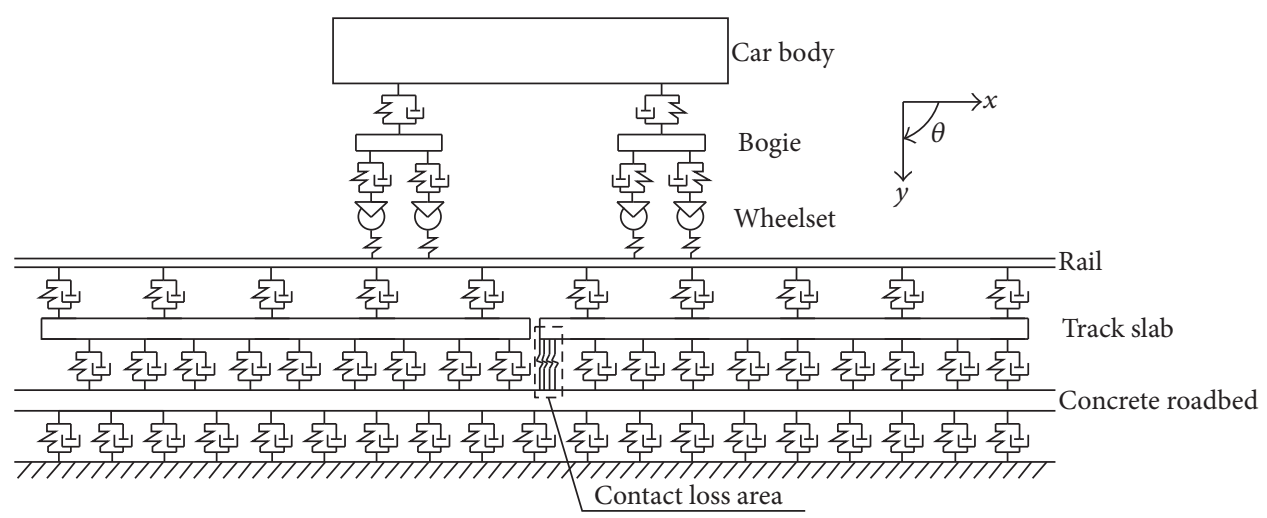

(a) Side view

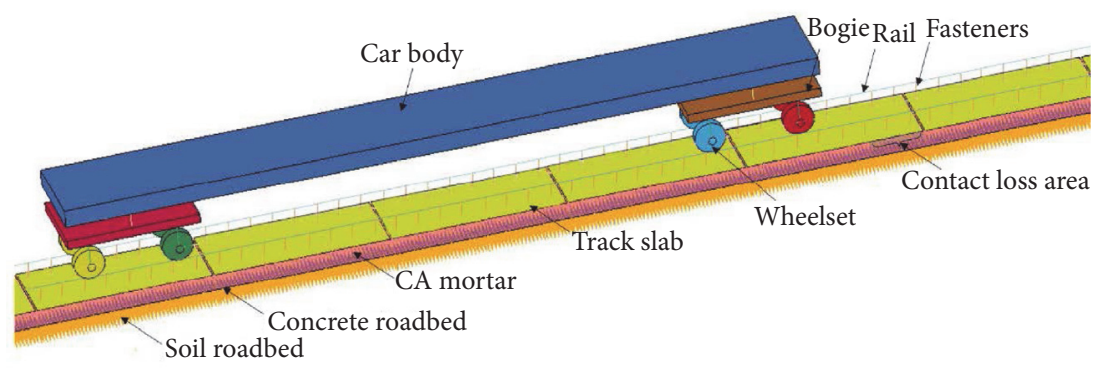

(b) 3D model

FIGURE 2: Vehicle-track vertical coupled vibration FEM model.

TABLE 1: Basic parameters of the vehicle subsystem.

\begin{tabular}{|c|c|}
\hline Parameters & Value \\
\hline Mass of car body & $39600 \mathrm{~kg}$ \\
\hline Mass of wheelset & $2500 \mathrm{~kg}$ \\
\hline $\begin{array}{l}\text { Inertia of vertical motion of } \\
\text { bogie }\end{array}$ & $1.283 \mathrm{~kg} \cdot \mathrm{m}^{2}$ \\
\hline $\begin{array}{l}\text { Damping of the primary } \\
\text { suspension of vehicle }\end{array}$ & $1.96 \times 10^{4} \mathrm{~N} \cdot \mathrm{s} / \mathrm{m}$ \\
\hline $\begin{array}{l}\text { Damping of the secondary } \\
\text { suspension of vehicle }\end{array}$ & $4.0 \times 10^{4} \mathrm{~N} \cdot \mathrm{s} / \mathrm{m}$ \\
\hline $\begin{array}{l}\text { Length between the truck } \\
\text { pivot centers }\end{array}$ & $17.5 \mathrm{~m}$ \\
\hline Mass of bogie & $3500 \mathrm{~kg}$ \\
\hline $\begin{array}{l}\text { Inertia of vertical motion } \\
\text { for the car }\end{array}$ & $1.94 \mathrm{~kg} \cdot \mathrm{m}^{2}$ \\
\hline $\begin{array}{l}\text { Vertical stiffness of the } \\
\text { primary suspension of } \\
\text { vehicle }\end{array}$ & $1.176 \times 10^{6} \mathrm{~N} / \mathrm{m}$ \\
\hline $\begin{array}{l}\text { Vertical stiffness of the } \\
\text { secondary suspension of } \\
\text { vehicle }\end{array}$ & $1.89 \times 10^{6} \mathrm{~N} / \mathrm{m}$ \\
\hline Wheel base for the bogie & $2.5 \mathrm{~m}$ \\
\hline Radius of the wheel & $0.43 \mathrm{~m}$ \\
\hline
\end{tabular}

track slab and soil roadbed were simplified as spring/damper elements. The CA mortar under the contact loss area was modeled as a series of nonlinear spring elements, whose stiffness can be calculated by

$$
k= \begin{cases}0 & x<h_{t} \\ \frac{E_{\mathrm{CA}}}{n \cdot h_{\mathrm{TCA}}} & x \geq h_{t},\end{cases}
$$

where $k$ refers to the nonlinear spring stiffness; $x$ refers to the compression value of CA mortar; $h_{t}$ refers to the contact loss height; $E_{\mathrm{CA}}$ refers to the elastic modulus of CA mortar; $h_{\mathrm{TCA}}$ refers to the height of CA mortar under contact loss area; $n$ refers to the number of nonlinear spring elements. The main parameters for track subsystem are presented in Table 2 .

(3) In the vertical coupling vibration model, there is a strong interaction between the rail and the wheel to combine the vehicle subsystem and track subsystem as one coupling system. This interaction has always been described with the Hertz Theory. The elastic deformations of the wheel and the rail form an ellipse contact area. The dimension of the contact ellipse depends on the normal force and the profiles of rail and wheel. In vehicle-track vertical dynamic coupling model, the wheel-rail contact was simplified as a Hertz spring. The relationship between the wheel-rail load $\left(P_{t}\right)$ and the wheelrail elastic compression $(\delta)$ can be expressed by

$$
P_{t}=\left[\frac{1}{G} \cdot \delta_{t}\right]^{2 / 3}
$$

in which $G$ is the constant of wheel-rail contact area, for the worn types of wheel treads, $G=4.57 R^{-0.149} \times 10^{-8}\left(\mathrm{~m} / \mathrm{N}^{2 / 3}\right)$; 
TABLE 2: Basic parameters of track subsystem.

\begin{tabular}{|c|c|}
\hline Parameters & Value \\
\hline Mass of rail per unit length & $60 \mathrm{~kg} / \mathrm{m}$ \\
\hline Young's modulus of rail & $2.06 \times 10^{5} \mathrm{Mpa}$ \\
\hline Poisson's ratio of rail & 0.3 \\
\hline Length of slab & $4.95 \mathrm{~m}$ \\
\hline Width of slab & $2.4 \mathrm{~m}$ \\
\hline Thickness of slab & $0.19 \mathrm{~m}$ \\
\hline Young's modulus of slab & $3.6 \times 10^{4} \mathrm{Mpa}$ \\
\hline Poisson's ratio of slab & 0.2 \\
\hline Density of slab & $2500 \mathrm{~kg} / \mathrm{m}^{3}$ \\
\hline Thickness of CA mortar & $0.05 \mathrm{~m}$ \\
\hline $\begin{array}{l}\text { Young's modulus of CA } \\
\text { mortar }\end{array}$ & $300 \mathrm{Mpa}$ \\
\hline $\begin{array}{l}\text { Vertical damping of CA } \\
\text { mortar }\end{array}$ & $3.46 \times 10^{4} \mathrm{~N} \cdot \mathrm{s} / \mathrm{m}$ \\
\hline Distance between fasteners & $0.625 \mathrm{~m}$ \\
\hline Vertical stiffness of fastener & $50 \mathrm{kN} / \mathrm{mm}$ \\
\hline $\begin{array}{l}\text { Vertical damping of } \\
\text { fastener }\end{array}$ & $7.5 \times 10^{4} \mathrm{~N} \cdot \mathrm{s} / \mathrm{m}$ \\
\hline Length of concrete roadbed & $125 \mathrm{~m}$ \\
\hline Width of concrete roadbed & $3.2 \mathrm{~m}$ \\
\hline $\begin{array}{l}\text { Thickness of concrete } \\
\text { roadbed }\end{array}$ & $0.3 \mathrm{~m}$ \\
\hline $\begin{array}{l}\text { Young's modulus of } \\
\text { concrete roadbed }\end{array}$ & $3.25 \times 10^{4} \mathrm{Mpa}$ \\
\hline $\begin{array}{l}\text { Poisson's ratio of concrete } \\
\text { roadbed }\end{array}$ & 0.2 \\
\hline $\begin{array}{l}\text { Density of concrete } \\
\text { roadbed }\end{array}$ & $2500 \mathrm{~kg} / \mathrm{m}^{3}$ \\
\hline $\begin{array}{l}\text { Vertical stiffness of soil } \\
\text { roadbed }\end{array}$ & $120 \mathrm{Mpa} / \mathrm{m}$ \\
\hline $\begin{array}{l}\text { Vertical damping of soil } \\
\text { roadbed }\end{array}$ & $1.0 \times 10^{5} \mathrm{~N} \cdot \mathrm{s} / \mathrm{m}$ \\
\hline
\end{tabular}

for the conical types of wheel treads, $G=3.86 R^{-0.115} \times 10^{-8}$ $\left(\mathrm{m} / \mathrm{N}^{2 / 3}\right)$, where $R$ represents the radius of the wheel.

3.2. The Irregularity of Track. The irregularity of track, which was overlaid by the stochastic irregular waves with different wavelengths, phases, and amplitudes, is an extremely complicated random process related to the length of railway. In this paper, the irregularity of the Germany high-speed low disturbance was applied to excite the vibration of vehicle and slab track, it can be represented by the power spectral density (PSD) function:

$$
S_{\nu}(\Omega)=\frac{A_{\nu}\left(\Omega_{C}^{2}\right)}{\left(\Omega^{2}+\Omega_{r}^{2}\right)\left(\Omega^{2}+\Omega_{C}^{2}\right)},
$$

where $S_{v}(\Omega)$ is the vertical power spectral density; $A_{v}$ is the roughness constant $\left(A_{v}=4.032 \times 10^{-7}\left(\mathrm{~m}^{2} \cdot \mathrm{rad} / \mathrm{m}\right)[9]\right)$; $\Omega_{C}$ and $\Omega_{r}$ are the cutoff frequency $\left(\Omega_{C}=0.8246(\mathrm{rad} / \mathrm{m})\right.$, $\Omega_{r}=0.0206(\mathrm{rad} / \mathrm{m})$ [9]); $\Omega$ is the spatial frequency of the irregularities.

\section{Dynamic Response of Vehicle Subsystem}

In order to figure out the influence of contact loss length on the dynamical characteristic of vehicle subsystem, a vehicletrack vertical coupled vibration FEM model was modeled using finite element package LS-DYNA. The length of contact loss varies from $0 \mathrm{~m}$ to $2 \mathrm{~m}$, and $200 \mathrm{~km} / \mathrm{h}, 250 \mathrm{~km} / \mathrm{h}$, and $300 \mathrm{~km} / \mathrm{h}$ were selected as the train speeds.

4.1. Acceleration of Vehicle Subsystem. The acceleration of vehicle subsystem, which includes the car body acceleration, bogie acceleration and wheel-set acceleration, is the main dynamical index for evaluating the driving comfort, in which the car body acceleration is the most important factor. The car body acceleration, bogie acceleration, and wheel-set acceleration are shown in Figure 3.

From Figure 3, it is clear that once the contact loss occurs, the vertical wheel-set acceleration increases with the increased contact loss length, and when it is more than $0.7 \mathrm{~m}$, the vertical bogie acceleration increases significantly with the increased contact loss length, whereas the vertical car body acceleration has a small increase when the contact loss length exceeds $1.5 \mathrm{~m}$. When the contact loss length increases from $0.0 \mathrm{~m}$ to $2.0 \mathrm{~m}$, the wheel-set acceleration increases approximately $34.40 \%$ at $200 \mathrm{~km} / \mathrm{h}$ of train speed, and the vertical bogie acceleration increases about $87.40 \%$ at $200 \mathrm{~km} / \mathrm{h}$ of train speed. When the contact loss length increases from $0.0 \mathrm{~m}$ to $1.5 \mathrm{~m}$, the car body acceleration only grows by $1.2 \%$, which means that the contact loss shorter than $1.5 \mathrm{~m}$ has bare influence on the car body acceleration. When the contact loss length increases to $2.0 \mathrm{~m}$, the car body acceleration increases about $13.4 \%$ to $0.35 \mathrm{~m} / \mathrm{s}^{2}$, less than the running smoothness index of $2.5 \mathrm{~m} / \mathrm{s}^{2}$ carried out by Zhai [23]. It can be concluded that due to the shock absorption of primary suspensions and second suspensions, when the train speed is no more than $300 \mathrm{~km} / \mathrm{h}$, the contact loss shorter than $2.0 \mathrm{~m}$ hardly affects the running smoothness of the vehicle.

4.2. Wheel-Rail Force. The wheel-rail force, which represents the interaction between the vehicle subsystem and track subsystem, is the main response to the track subsystem state and acts as the dynamic load to the track. The rate of wheel load reduction acting as one of the ride safety index can be calculated by the following equation:

$$
\delta=\frac{\left(\bar{P}-P_{\min }\right)}{\bar{P}}
$$

in which $\delta$ represents the rate of wheel load reduction; $\bar{P}$ is the average value of the wheel-rail force; $P_{\min }$ is the minimum value of the wheel-rail force.

The wheel-rail force curve in time domain at $300 \mathrm{~km} / \mathrm{h}$ of train speed is shown in Figure 4(a). It can be seen that when the train passes through the area with contact loss of $0.7 \mathrm{~m}$ in length, the wheel-rail force reaches the maximum value; compared with passing through the normal slab without contact loss, the maximum wheel-rail force increases significantly and the minimum wheel-rail force keeps constant. The relationships between the contact loss 


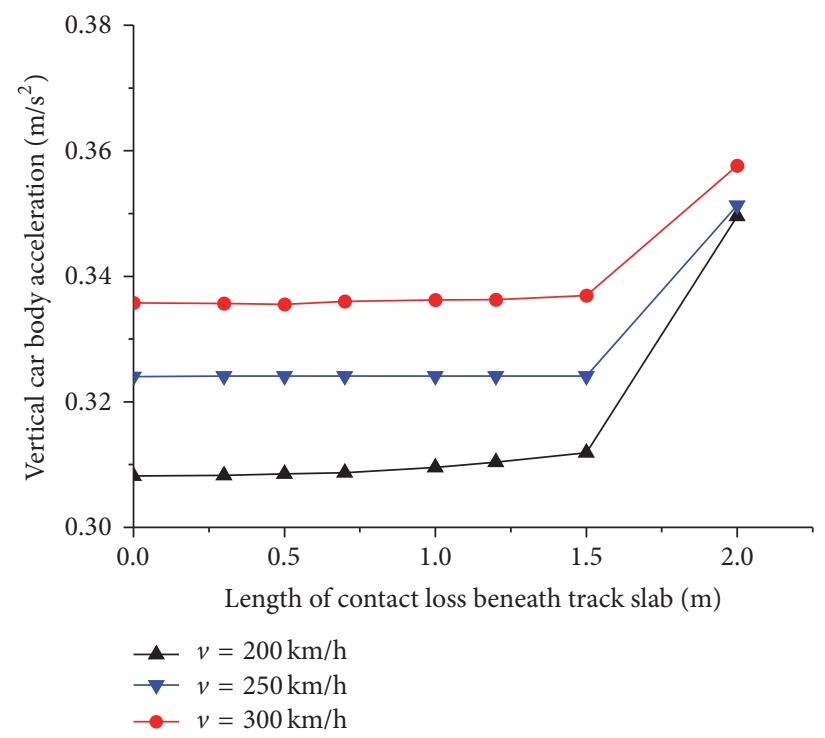

(a) Vertical car body acceleration

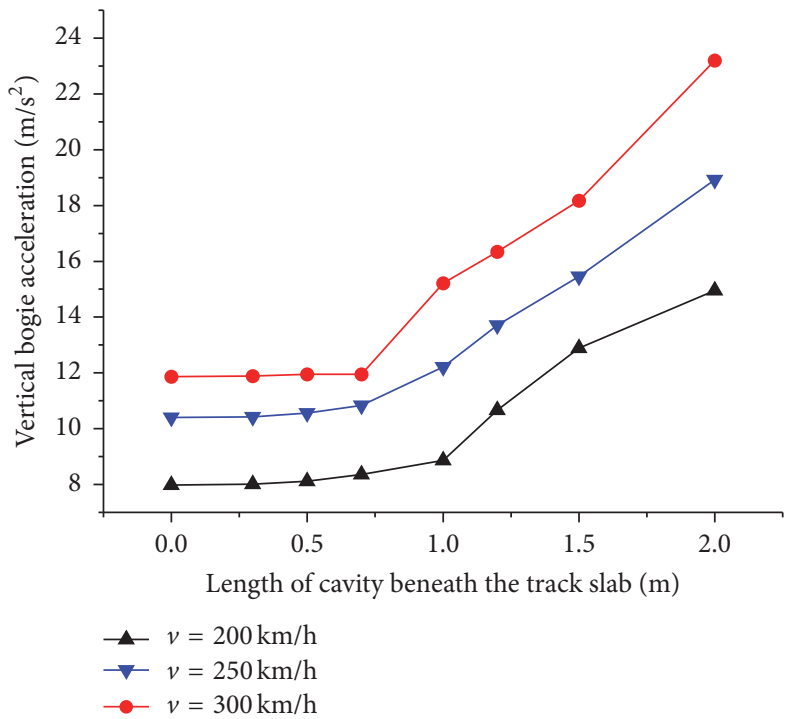

(b) Vertical bogie acceleration

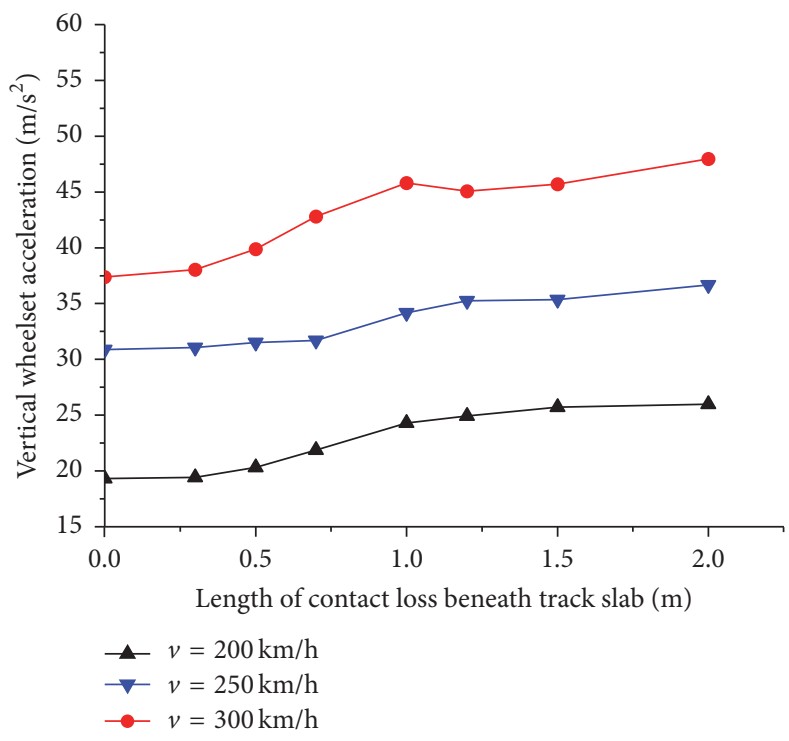

(c) Vertical wheel-set acceleration

FIGURE 3: Influence of contact loss length on vertical acceleration of vehicle subsystem.

length and the maximum wheel-rail force at different train speeds are shown in Figure 4(b), and it can be found that, with the increased contact loss length, the maximum wheelrail force increases gradually, especially for the contact loss length ranging from $0.5 \mathrm{~m}$ to $1.5 \mathrm{~m}$. Comparing these curves in Figure 4(b), it is clear that the faster the train speed is, the greater the maximum wheel-rail force is.

Figure 4(c) shows the influence of the contact loss length on the rate of wheel load reduction. It indicates that, for a $200 \mathrm{~km} / \mathrm{h}$ train speed, when the contact loss length is less than $1.2 \mathrm{~m}$, it hardly affects the rate of wheel load reduction, when the contact loss length increases to $2.0 \mathrm{~m}$, the rate of wheel load reduction only grows by $7.7 \%$, while for a $250 \mathrm{~km} / \mathrm{h}$ train speed, when the contact loss length is less than $1.0 \mathrm{~m}$, it barely has influence on the wheel load reduction rate, and when the contact loss length increases to $2.0 \mathrm{~m}$, the rate of wheel load reduction rises about $14.5 \%$. For a $300 \mathrm{~km} / \mathrm{h}$ train speed, when the contact loss length is less than $0.7 \mathrm{~m}$, the wheel load reduction barely changes with the increased contact loss length, and when the contact loss length increases to $2.0 \mathrm{~m}$, the rate of wheel load increases about $39.0 \%$ to 0.5541 . According to the research conducted by Zhai [23], in order to ensure the ride safety, the wheel load reduction rate of highspeed vehicle should not exceed 0.6 . It can be concluded that for train speed no more than $300 \mathrm{~km} / \mathrm{h}$, the contact loss which is less than $2.0 \mathrm{~m}$ barely affects the ride safety.

\section{Dynamic Response of Track Subsystem}

Due to the excitation of rail irregularity, the train load will result in the vibration of track system. With the deterioration 


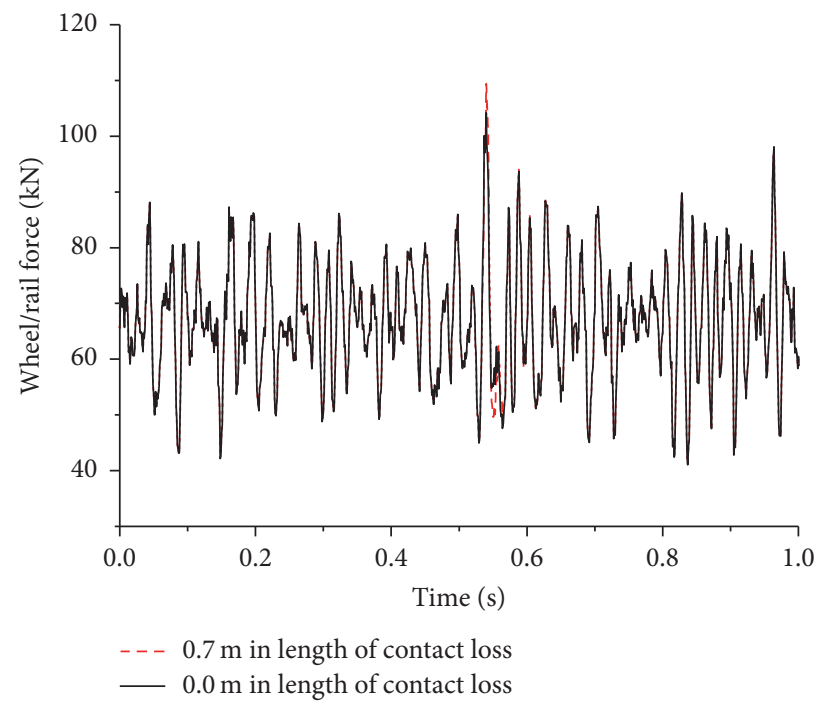

(a) Time domain curve of Wheel-rail force

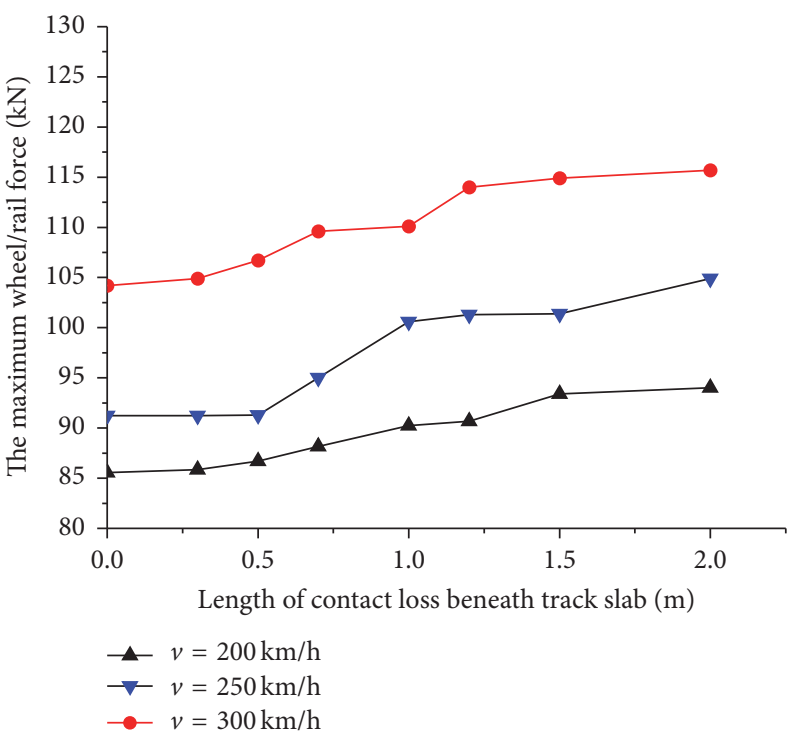

(b) Maximum wheel-rail force

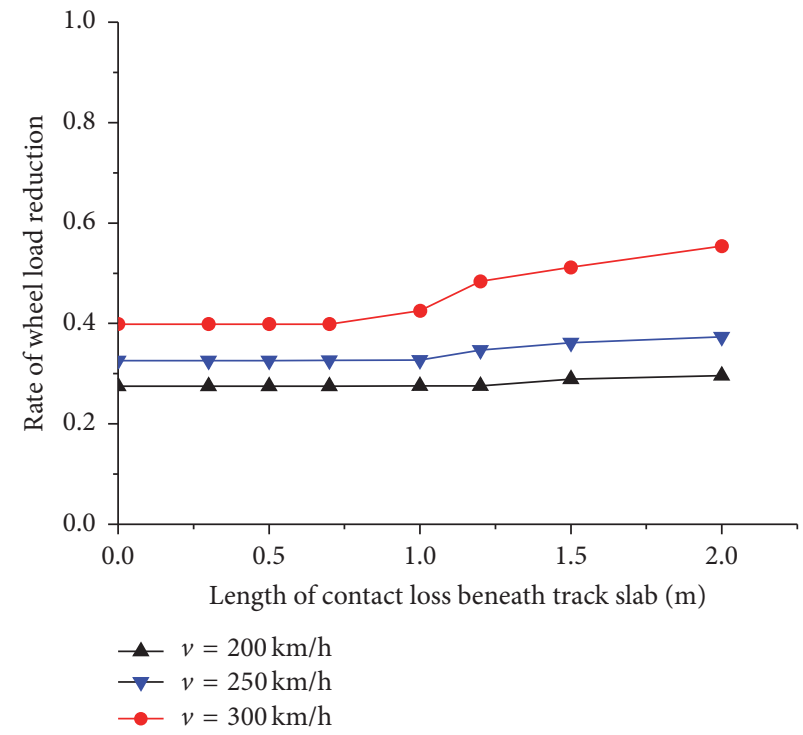

(c) Rate of wheel load reduction

FIGURE 4: Influence of contact loss length on the wheel-rail force.

of track and the increased train speed, the vibration displacement of track system increases gradually. Once the vibration displacement is plethoric, it will cause the damage of track system which has an important impact on the ride smoothness and safety. In this case, the train has to slow down or stop. Therefore, the dynamic response of track system has important significance on ensuring the ride smoothness and safety.

5.1. Displacement of Rail. The vibration displacement of rail plays an important role in the rail irregularity, and the plethoric displacement of rail may affect the ride safety. Figure 5(a) shows the relation between the length of contact loss and the vibration displacement of rail. The rail vibration displacement in the time domain is shown in Figure 5(b).
From Figure 5(a), it can be found that when the contact loss length is no more than $0.5 \mathrm{~m}$, the increasing contact loss length has slight influence on the vibration displacement of rail. When the length of contact loss beneath the track slab exceeds $0.5 \mathrm{~m}$, the displacement of rail has a significant upward trend. Compared with the normal slab without contact loss, when the contact loss length becomes $1.5 \mathrm{~m}$, for a $200 \mathrm{~km} / \mathrm{h}$ train speed, the displacement of rail increases about $75.3 \%$; for a $250 \mathrm{~km} / \mathrm{h}$ train speed, it increases about $79.32 \%$; for a $300 \mathrm{~km} / \mathrm{h}$ train speed, it grows about $83.78 \%$, while for the track slabs with $2.0 \mathrm{~m}$ contact loss, when the train is running at the speed of $300 \mathrm{~km} / \mathrm{h}$, there is a slight decline in the increase rate of the rail displacement.

Figure 5(b) indicates that when the contact loss length increases to $1.5 \mathrm{~m}$, the vibration amplitude of rail is greater 


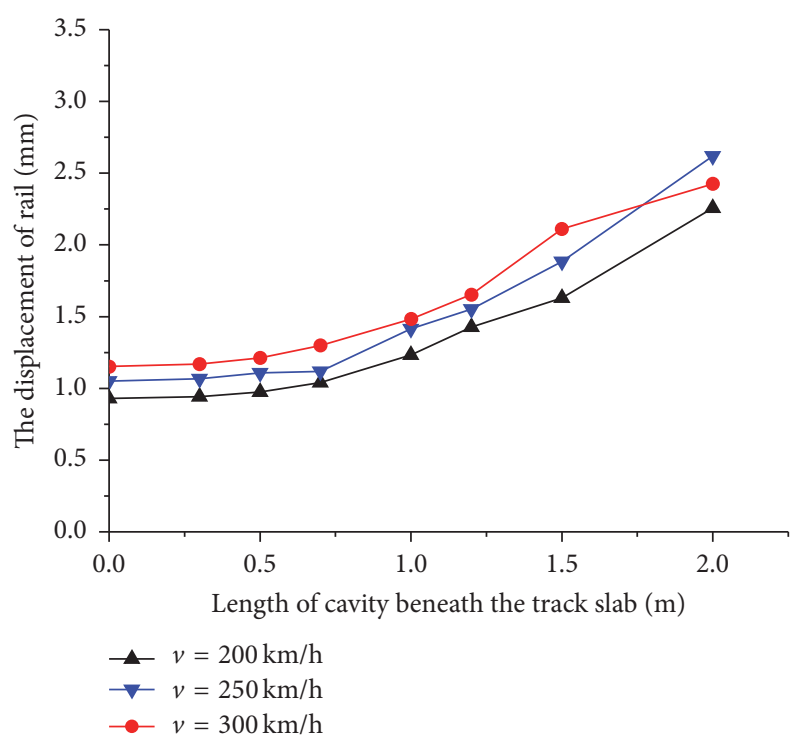

(a) Rail displacement

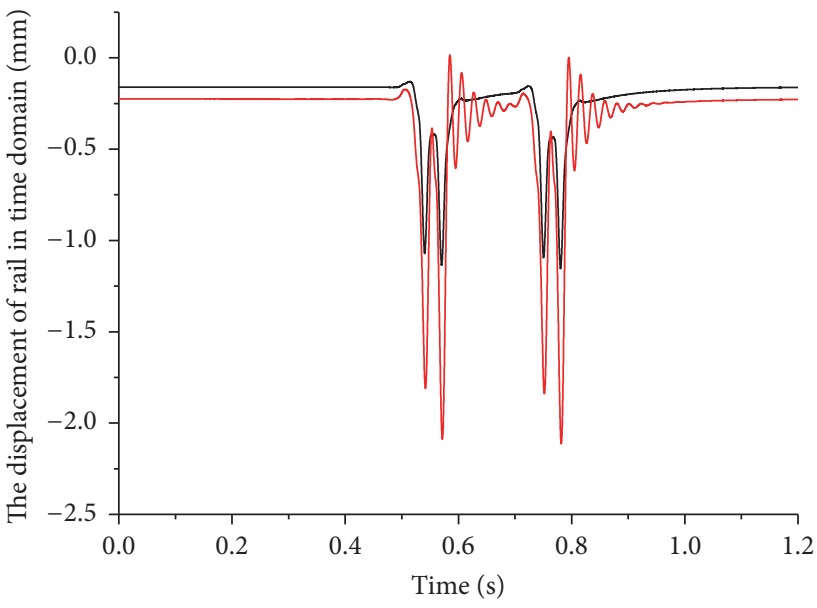

- Normal slab without contact loss

— $1.5 \mathrm{~m}$ in length of contact loss

(b) Time-displacement curve of rail displacement

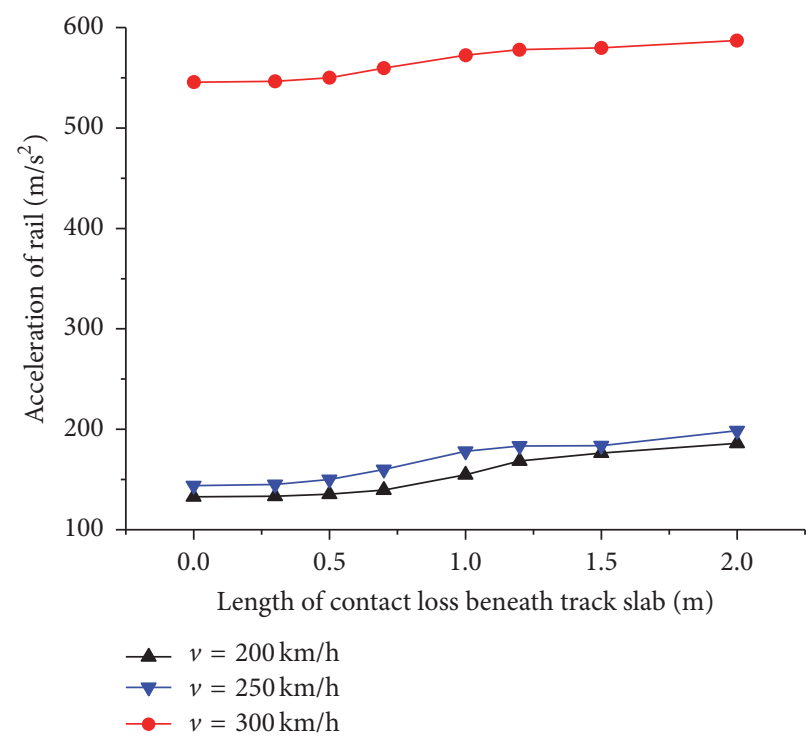

(c) Effects of the contact loss length on the rail acceleration

FIGURE 5: Influence of contact loss length on the dynamic responses of rail.

than that without contact loss. For the normal slab without contact loss, after the train passed, the displacement of rail gradually reduces to the original value, while for the slab with contact loss of $1.5 \mathrm{~m}$ in length, after the train passed, there is a significant vibration of rail before being back to the original condition, which means that, with the increase of contact loss length, the dynamic effect on rail increases significantly.

Figure 5(c) shows the influence of contact loss length on the rail acceleration. From Figure 5(c), it can be seen that the contact loss which is shorter than $0.5 \mathrm{~m}$ has bare influence on the rail acceleration. Once the contact loss length exceeds $0.5 \mathrm{~m}$, the rail acceleration increases progressively with the increase of the contact loss length, especially when the contact loss length is in the range of $0.5 \mathrm{~m}$ to $1.2 \mathrm{~m}$. When the contact loss length increases to $2.0 \mathrm{~m}$, for a $200 \mathrm{~km} / \mathrm{h}$ and a $250 \mathrm{~km} / \mathrm{h}$ train speed, the rail acceleration increases approximately $40 \%$, and for a $300 \mathrm{~km} / \mathrm{h}$ train speed, the train acceleration only increases about $7.6 \%$.

5.2. Displacement and Acceleration of Track Slab. The influence of contact loss length on the track displacement is shown in Figure 6(a). It indicates that the vibration displacement of track slab is strongly related to the contact loss length. The contact loss beneath the track slab leads to the rapid increase of slab displacement. When the contact loss length increases to $1.5 \mathrm{~m}$, the displacement of track at a $300 \mathrm{~km} / \mathrm{h}$ train speed is the greatest $(2.358 \mathrm{~mm})$, which is 9.32 times of that of the normal slab without contact loss, while the displacement of track at $200 \mathrm{~km} / \mathrm{h}$ is the smallest $(1.758 \mathrm{~mm})$, which is 6.40 times of that of the normal slab without contact loss. This 


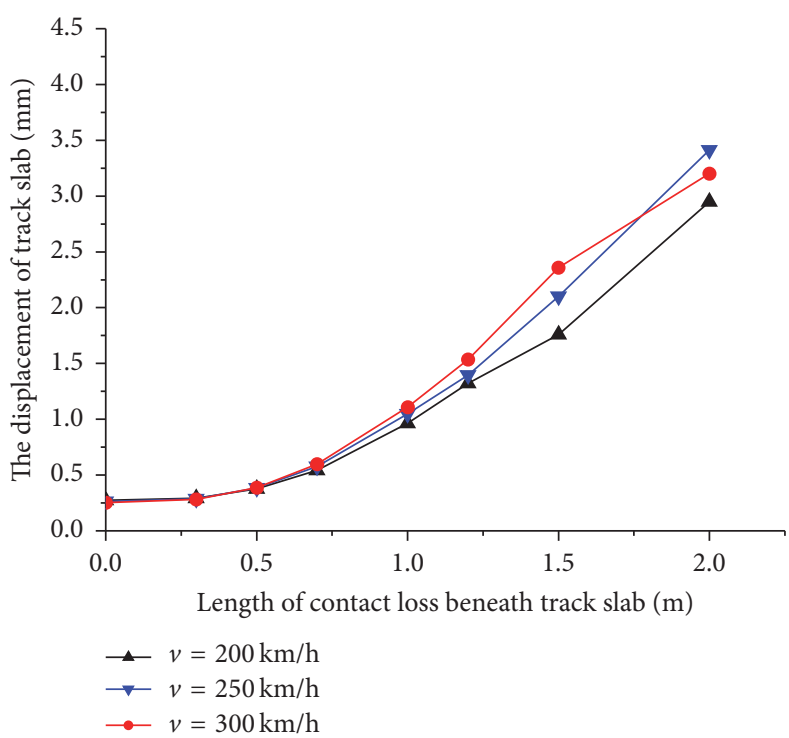

(a) The displacement of track slab

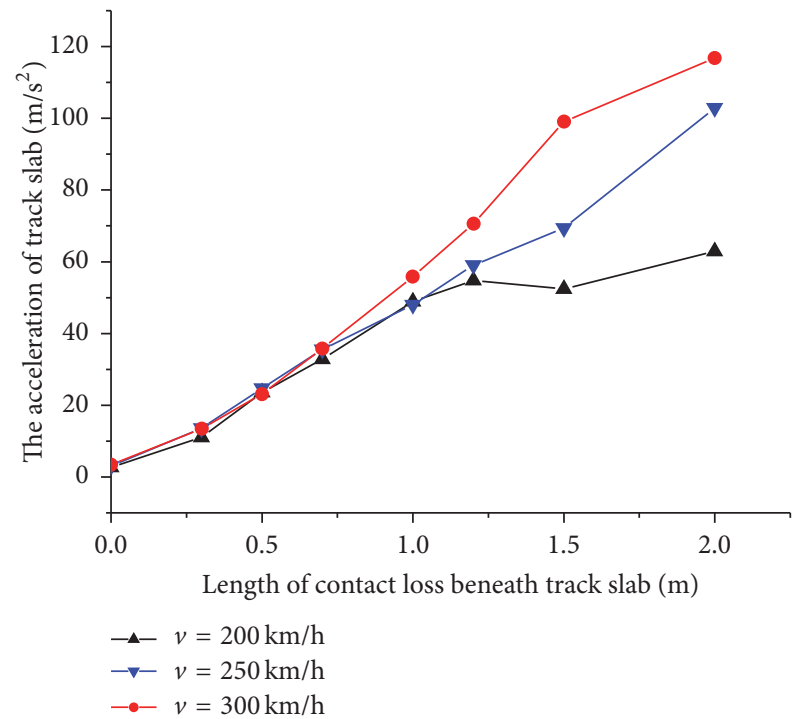

(b) The acceleration of track slab

FIGURE 6: Influence of contact loss length on the dynamic characteristic of track slab.

means that at a higher train speed, the contact loss which is in the range of $0.0 \mathrm{~m}$ to $1.5 \mathrm{~m}$ has more impact on the displacement of track. When the contact loss length reaches $2.0 \mathrm{~m}$, the displacement of track at $250 \mathrm{~km} / \mathrm{h}$ becomes the biggest, instead of at $300 \mathrm{~km} / \mathrm{h}$, and it reaches $3.418 \mathrm{~mm}$ and 12.99 times of that of the normal slab.

Figure 6(b) shows the relationship between the contact loss length and the track acceleration. It can be seen that when the contact loss length is less than $1.2 \mathrm{~m}$, with the increased contact loss length, the track acceleration is likely to increase linearly. When the contact loss length increases to $1.2 \mathrm{~m}$, at the train speed of $200 \mathrm{~km} / \mathrm{h}, 250 \mathrm{~km} / \mathrm{h}$, and $300 \mathrm{~km} / \mathrm{h}$, the track accelerations increase to $54.82 \mathrm{~m} / \mathrm{s}^{2}, 59.06 \mathrm{~m} / \mathrm{s}^{2}$, and $70.62 \mathrm{~m} / \mathrm{s}^{2}$, which are almost 20 times of that of the normal slab. When the contact loss length is over $1.2 \mathrm{~m}$, for a $200 \mathrm{~km} / \mathrm{h}$ train speed, the acceleration of track almost keeps the same level, while for the train speed of $250 \mathrm{~km} / \mathrm{h}$ and $300 \mathrm{~km} / \mathrm{h}$, the accelerations of track increase continuously, and when the length of contact loss reaches $2.0 \mathrm{~m}$, the track accelerations reach $102.87 \mathrm{~m} / \mathrm{s}^{2}$ and $116.83 \mathrm{~m} / \mathrm{s}^{2}$, respectively.

5.3. Displacement and Acceleration of Concrete Roadbed. Figure 7(a) represents the influence of contact loss length on the vibration displacement of concrete roadbed. It is clear that for the track with contact loss which is shorter than $1.2 \mathrm{~m}$, the vibration displacement of concrete roadbed grows slightly with the increased contact loss length. When the contact loss length increases from $0.0 \mathrm{~m}$ to $1.2 \mathrm{~m}$, for a $200 \mathrm{~km} / \mathrm{h}$ train speed, the displacement of concrete roadbed grows by $2.09 \%$; for a $250 \mathrm{~km} / \mathrm{h}$ train speed and a $300 \mathrm{~km} / \mathrm{h}$ train speed, the displacements increase about $3.18 \%$ and $4.43 \%$, respectively, while for the contact loss length exceeding $1.2 \mathrm{~m}$, the displacements of concrete roadbed are almost at the same value.
Figure 7(b) shows the influence of the contact loss length on the acceleration of concrete roadbed. It can be seen that when the length of contact loss beneath the track slab is less than $0.5 \mathrm{~m}$, the acceleration of concrete roadbed reduces with the increased contact loss length. After that, there is an upward trend for the acceleration of concrete roadbed until the contact loss length reaches $1.2 \mathrm{~m}$; then, it almost keeps the same level.

From Figures $7(a)$ and $7(b)$, it can be found that the concrete roadbed displacement is always in the range of $0.250 \mathrm{~mm}$ to $0.280 \mathrm{~mm}$ and the acceleration is always in the range of $0.2 \mathrm{~m} / \mathrm{s}^{2}$ to $1.0 \mathrm{~m} / \mathrm{s}^{2}$, and it can be concluded that the contact loss length has very small influence on the displacement and acceleration of the concrete roadbed.

\section{Experimental Procedure}

6.1. Model Preparation. There were two CRTS-I Slab Track models arranged in this test. Based on the construction process of CRTS-I Slab Track in Chinese passenger dedicated line, its prototype was constructed and used as the test model. The model preparation process is shown in Figure 8. The track slab was prefabricated as a two-way prestressed concrete slab, the concrete roadbed and the cylindrical bollards were made with C40 reinforced concrete through field construction. The mechanical performance of CA mortar met the tentative requirements of the CA mortar for the CRTS-I Slab Track in passenger dedicated line.

6.2. Train Load. In this test, the train load was generated by the customized ZSS50 excitation car (as shown in Figure 9) which consisted of a left experimental flat car and a right vibration car. There are two wheel-sets of experimental flat car; the front wheel-set was excitation wheel-set and the rear 


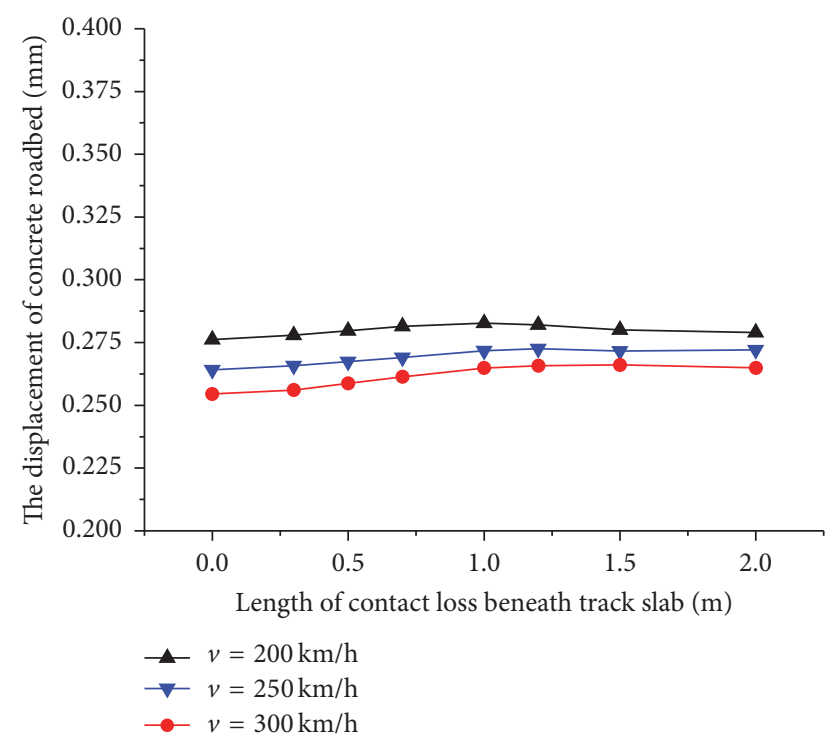

(a) The displacement of concrete roadbed

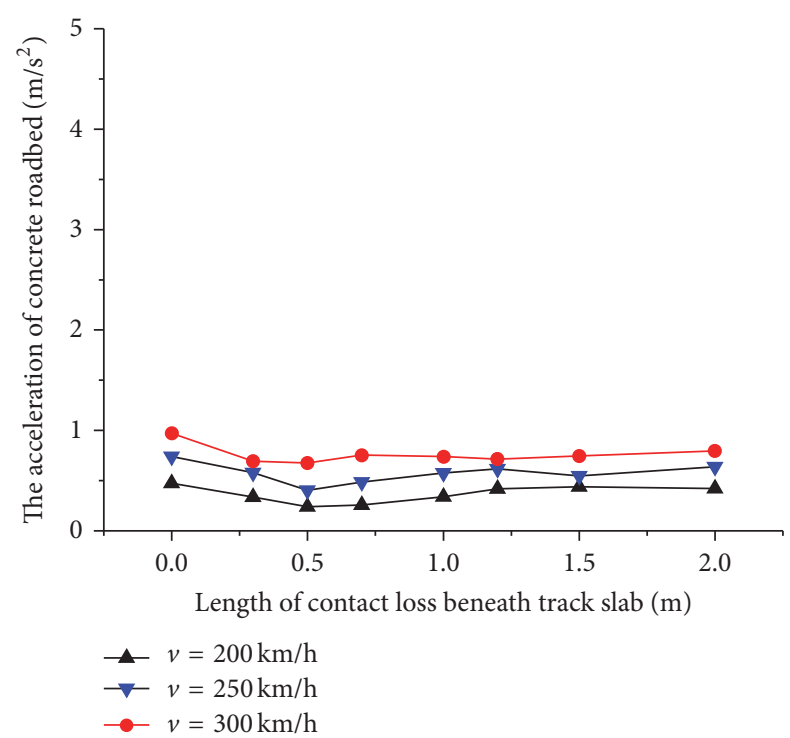

(b) The acceleration of concrete roadbed

FIGURE 7: Influence of contact loss length on the dynamic characteristic of concrete roadbed.

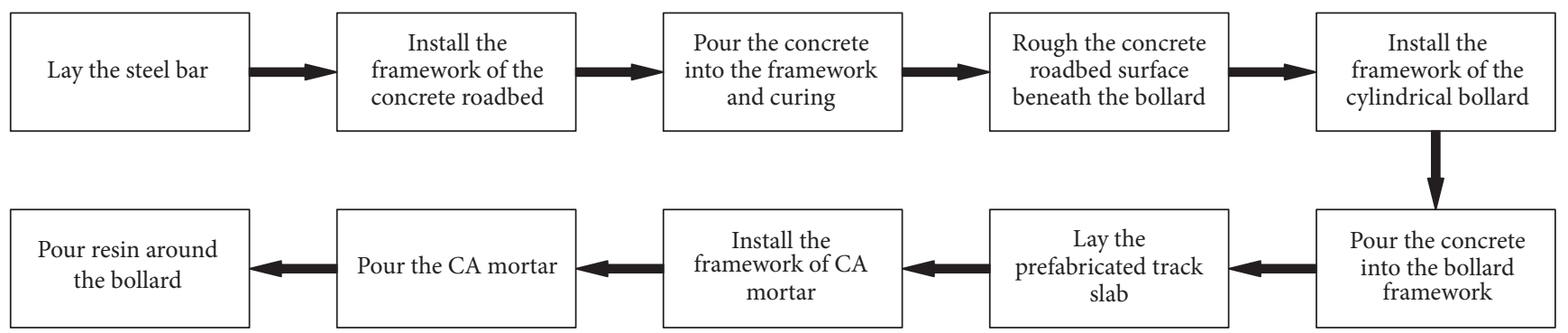

FIGURE 8: Production process of model.

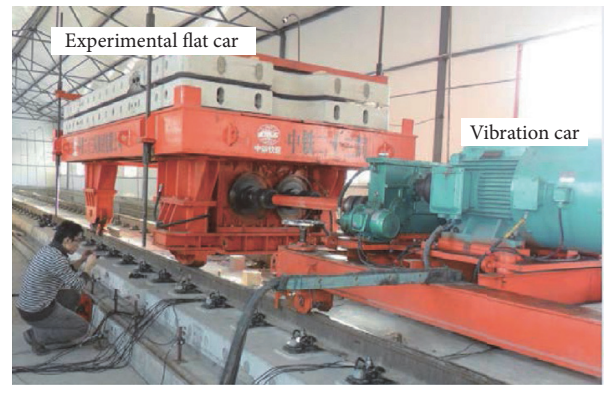

FIgURE 9: ZSS50 excitation car.

wheel-set was moving wheel; the length between the two wheel-sets is $3 \mathrm{~m}$. The experimental flat simulates a bogie of high-speed vehicle. As shown in Figure 9, track slabs can be placed on the experimental flat car to make the static wheel load keeping at a certain level. There is a pair of eccentric blocks locked on the excitation car, and it was connected with the vibration motor placed on the vibration car. When the vibration motor is turning on, the rotating eccentric blocks can generate a sine vibration force to simulate the dynamic wheel load. The frequency and amplitude of dynamic wheel load vary with the different mass of eccentric blocks and rotated speed of eccentric motor. The excitation frequency can range from $10 \mathrm{~Hz}$ to $30 \mathrm{~Hz}$; the ambient temperature for operating ranges from $-45^{\circ} \mathrm{C}$ to $45^{\circ} \mathrm{C}$.

6.3. Dynamic Test. Two Slabs were provided for the dynamic test, and the CA mortar under the right end of Number 2 slab was excavated to simulate contact loss beneath the track slab (as shown in Figure 10(b)). Based on the research conducted by Liu [24], the contact loss beneath the track slab which exceeds $1.538 \mathrm{~m}$ would lead to the plethoric pulling force of fasteners and the vertical rail displacement. This dynamic test focused on the influence of the contact loss length ranging from $0.0 \mathrm{~m}$ to $1.2 \mathrm{~m}$ on the dynamic characteristics of the slab track. During the test, the CRTS-I Slab Track was subjected to the repeated load generated by the ZSS50 excitation car; the vibration wheel-set was applied on the middle of Number 2 slab (the triangle areas shown in Figure 10(a)); the excitation frequency was $15 \mathrm{~Hz}$. There were two track slabs placed on the experimental flat car to add the static wheel load to $55 \mathrm{kN}$; the dynamic wheel load ranged from $46 \mathrm{kN}$ to $64 \mathrm{kN}$. 


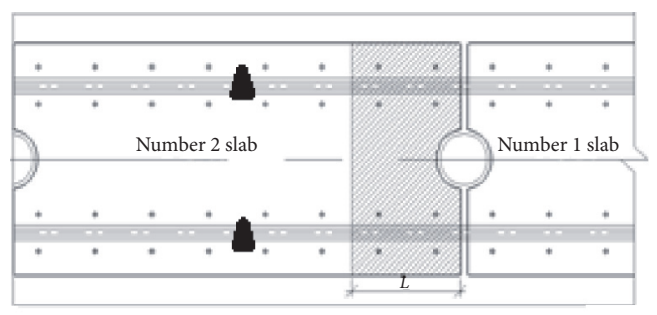

The shadow area present in the cavity beneath the track slab $L$ is the cavity length

(a) The contact loss position

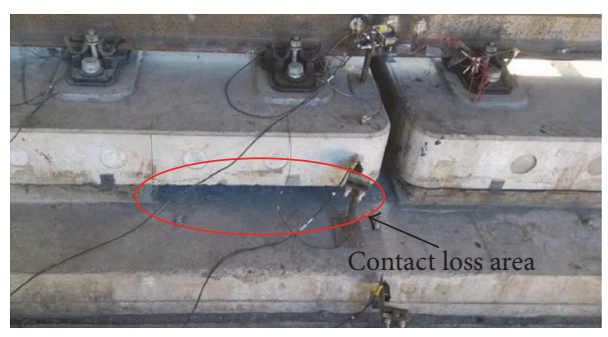

(b) The excavated contact loss beneath the track slab

FIGURE 10: The cement emulsified asphalt contact loss in the prototype experiment.

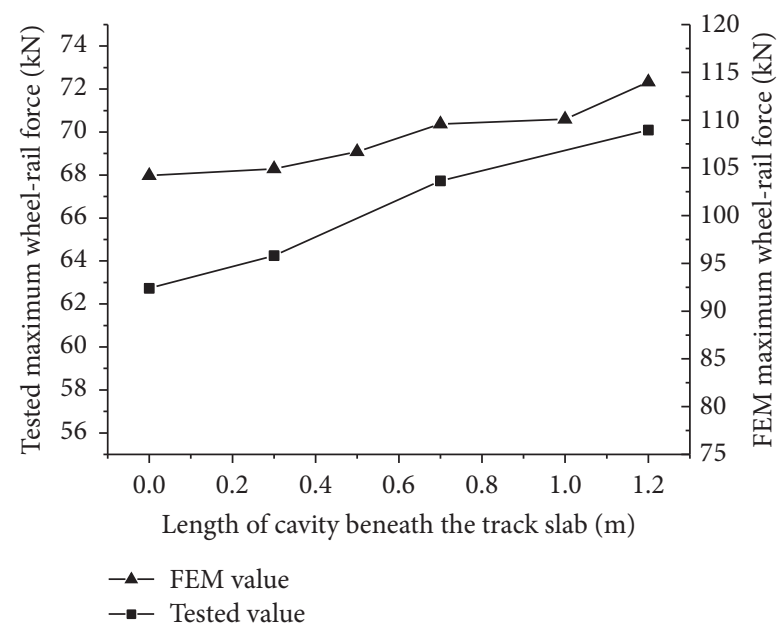

Figure 11: Maximum wheel-rail force with different contact loss length.

\subsection{Test Results}

6.4.1. Wheel-Rail Force. During the test process, the wheelrail force was tested using the shear difference method. Figure 11 shows the maximum wheel-rail force change with the length of the contact loss beneath the track slab.

From Figure 11, it is clear that with the increased contact loss length, the wheel-rail force increases significantly. For the excitation car on the normal slab track without the contact loss, the tested maximum wheel-rail force was $62.73 \mathrm{kN}$. When the contact loss of $0.3 \mathrm{~m}$ in length occurred, the tested maximum wheel-rail force rose about $2.4 \%$, then for the contact loss length increased to $1.2 \mathrm{~m}$, the tested maximum wheel-rail force rose about $11.7 \%$.

For a $300 \mathrm{~km} / \mathrm{h}$ train speed, if the length of one vehicle is $22 \mathrm{~m}$, the wheel passing frequency is $15 \mathrm{~Hz}$ [23]. So the experimental results should be compared with the results of the vehicle-track vertical vibration FEM model at a train speed of $300 \mathrm{~km} / \mathrm{h}$. Comparing Figures 11 and 4(b), it can be found that the maximum wheel-rail force of FEM model is much bigger than that of experimental test. The reason should include two sides. For one thing, the static wheel load of FEM model $(68.25 \mathrm{kN})$ is bigger than that of experiment test. For another, the irregularity of FEM model significantly magnifies the dynamic response of wheel-rail force. Even though the maximum wheel-rail forces of FEM model and experimental test are not at the same level, it has the same upward trend with the increased contact loss length. The contact loss length would lead to the wheel-rail force increase, especially for the contact loss longer than $0.3 \mathrm{~m}$.

6.4.2. Accelerations of Rail and Track Slab. According to the analysis results of vehicle-track vertical vibration FEM model, it can be found that, compared with the dynamic characteristic of rail and concrete roadbed, the dynamic characteristic of track slab is more sensitive to the change of the contact loss length. During the test, the rail acceleration and the track acceleration were measured as is shown in Figure 12.

Because of the bigger wheel-rail force and the excitation of irregularity in FEM model, the tested dynamic acceleration of rail and track slab is smaller than that of FEM model. From Figure 12, it can be concluded that when the contact loss is longer than $0.3 \mathrm{~m}$, the acceleration of rail has a significant increase with the increased contact loss length, and when the contact loss beneath the track slab occurs, the acceleration of track slab increases rapidly. When the contact loss length increases from $0.0 \mathrm{~m}$ to $1.2 \mathrm{~m}$, compared with the normal track slab without contact loss, the tested rail acceleration rose $53.7 \%$ and the FEM rail acceleration rose about 5.98\%, while the tested track slab acceleration increased by 11.35 times and the FEM acceleration increased by 20.71 times.

It can be concluded that the dynamic characteristic of track slab is more sensitive to the contact loss; once the contact loss occurs, it would lead to a rapid increase of track acceleration, while the contact loss longer than $0.7 \mathrm{~m}$ would cause a significant increase of rail acceleration.

\section{Conclusions}

In this study, the vehicle-track vertical coupling vibration FEM model was established to analyze the effects of the contact loss on the dynamic characteristic of the vehicle subsystem and the track subsystem at different train speeds. Then, the prototype experimental test was performed to verify the FEM model results. During the test, the customized 


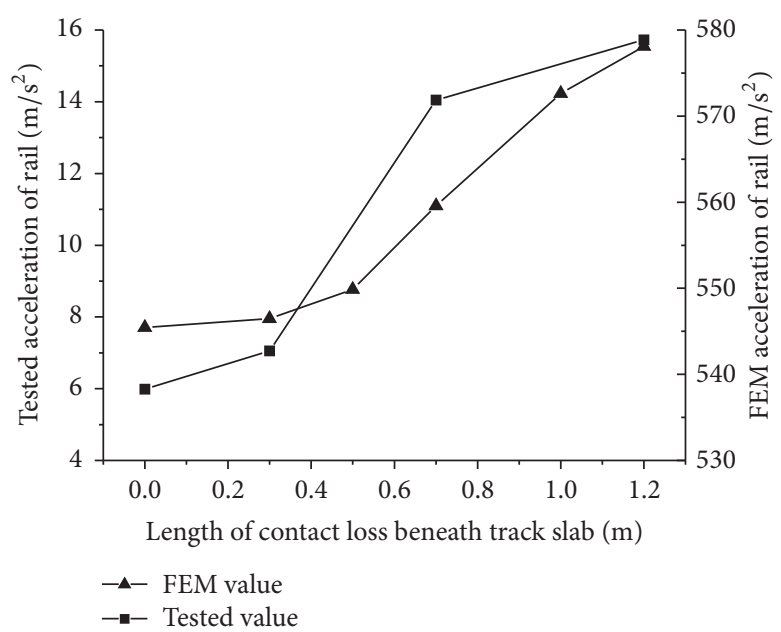

(a) Tested acceleration of rail

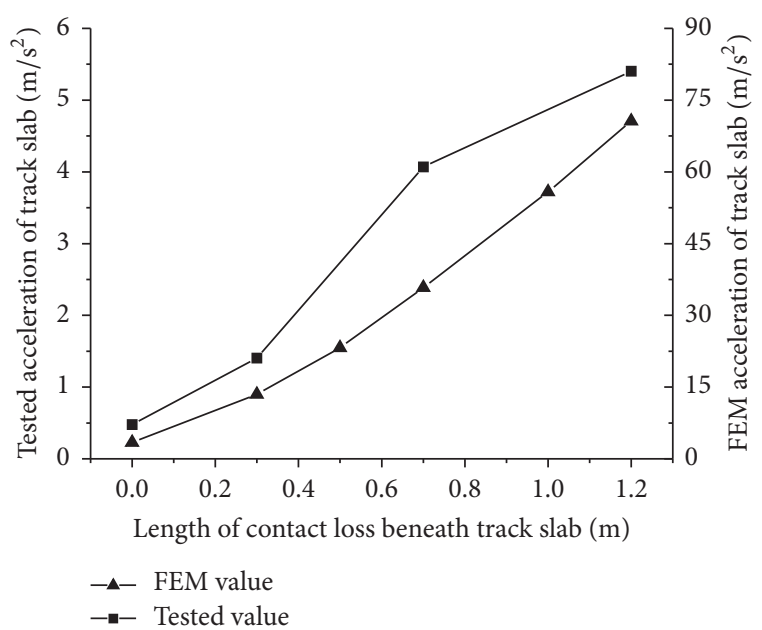

(b) Tested acceleration of track

FIGURE 12: The tested results of the influence of contact loss length on the dynamic responses of track subsystem.

ZSS50 excitation car was applied on the prototype of CRTSI Slab Track with excavated CA mortar in different lengths which simulated the contact loss beneath the track slab. According to the analysis of the FEM model and the prototype experimental test, the following conclusions can be drawn:

(1) The vertical wheel-set acceleration is strongly dependent on the contact loss length, and the vertical bogie acceleration increases significantly once the contact loss length exceeds $0.7 \mathrm{~m}$, whereas the vertical car body acceleration increases slightly when the contact loss length exceeds $1.5 \mathrm{~m}$. Due to the shock absorption of primary suspensions and second suspensions, for a train speed no more than $300 \mathrm{~km} / \mathrm{h}$, the contact loss less than $2.0 \mathrm{~m}$ hardly affects the running smoothness of vehicle.

(2) With the increased contact loss length, the maximum wheel-rail force increases gradually, especially for the contact loss length in the range of $0.5 \mathrm{~m}$ to $1.5 \mathrm{~m}$. There is a threshold value for the length of contact loss; once it is exceeded, the increase of the rate of wheel load reduction would occur. For the train speed of $200 \mathrm{~km} / \mathrm{h}, 250 \mathrm{~km} / \mathrm{h}$, and $300 \mathrm{~km} / \mathrm{h}$, the threshold values are $1.2 \mathrm{~m}, 1.0 \mathrm{~m}$, and $0.7 \mathrm{~m}$, respectively. For the train speed less than $300 \mathrm{~km} / \mathrm{h}$, the contact loss shorter than $2.0 \mathrm{~m}$ barely leads to ride safety problem.

(3) For the track subsystem, the slab is the most sensitive component. Once the contact loss beneath the track slab occurs, the vibration displacement and the acceleration of track slab rise rapidly. When the length of contact loss beneath the track slab exceeds $0.5 \mathrm{~m}$, there is a significant increase in the vibration amplitude and acceleration of rail. However, the contact loss length has little influence on the displacement and acceleration of the concrete roadbed.

(4) The results of prototype experimental test are in accordance with those of the vehicle-track vertical coupling vibration FEM model. Integrating the FEM model results and the experimental test results, the dynamic characteristics of the track subsystem are related to the contact loss length, especially for the track slab.

\section{Disclosure}

The results and opinions presented are those of the authors and do not necessarily reflect those of the sponsoring agencies.

\section{Competing Interests}

The authors declare that there is no conflict of interests regarding the publication of this paper.

\section{Acknowledgments}

This research is sponsored by the National Natural Science Foundation of China (nos. U1434208 and 51578472) and the China Railway Corporation (no. 2015G001-F), whose supports are gratefully acknowledged.

\section{References}

[1] M. J. M. M. Steenbergen, A. V. Metrikine, and C. Esveld, "Assessment of design parameters of a slab track railway system from a dynamic viewpoint," Journal of Sound and Vibration, vol. 306, no. 1-2, pp. 361-371, 2007.

[2] C. Esveld, "Recent developments in slab track," European Railway Review, pp. 81-85, 2003.

[3] F. Wang, Z. Liu, T. Wang, and S. Hu, "A novel method to evaluate the setting process of cement and asphalt emulsion in CA mortar," Materials and Structures/Materiaux et Constructions, vol. 41, no. 4, pp. 643-647, 2008.

[4] J. Ren, X. Li, R. Yang, P. Wang, and P. Xie, "Criteria for repairing damages of CA mortar for prefabricated framework-type slab 
track," Construction and Building Materials, vol. 110, pp. 300311, 2016.

[5] Q. Yuan, W. Liu, Y. Pan, D. Deng, and Z. Liu, "Characterization of cement asphalt mortar for slab track by dynamic mechanical thermoanalysis," Journal of Materials in Civil Engineering, vol. 28, no. 3, Article ID 04015154, 2016.

[6] R. Chen, P. Wang, and X.-K. Wei, "Manufacturing process of cement asphalt mortar and its applications in slab track," Journal of Nanoelectronics \& Optoelectronics, vol. 7, no. 2, pp. 155-161, 2012.

[7] P. Wang, H. Xu, and R. Chen, "Effect of cement asphalt mortar debonding on dynamic properties of CRTS II slab ballastless track," Advances in Materials Science and Engineering, vol. 2014, Article ID 193128, 8 pages, 2014.

[8] X. Zheng, J. Liu, Z. Zeng et al., "Rheological behavior, segregation, microstructure, and construction quality of cementemulsified asphalt mortar with associative thickener," Journal of Materials in Civil Engineering, vol. 27, no. 11, Article ID 04015025, 2015.

[9] M. Madhkhan, M. Entezam, and M. E. Torki, "Mechanical properties of precast reinforced concrete slab tracks on nonballasted foundations," Scientia Iranica, vol. 19, no. 1, pp. 20-26, 2012.

[10] W. Shi, Study on Effect of Slab Track Structure Defect on Dynamic Performance, Southwest Jiaotong University, Chengdu, China, 2011 (Chinese).

[11] J. Xiang, D. He, and Q. Zeng, "Effect of cement asphalt mortar disease on dynamic performance of slab track," Journal of Central South University: Science and Technology, vol. 40, no. 3, pp. 791-796, 2009.

[12] P. Li, X. Liu, and G. Li, "Influence of CA mortar void on dynamic characteristics of unit slab track on bridge," China Railway Science, vol. 35, no. 3, pp. 20-27, 2014 (Chinese).

[13] X. H. Zeng, Y. J. Xie, and D. H. Deng, "Conductivity behavior of the fresh CA mortar and its relationship with the fluidity properties," Construction and Building Materials, vol. 36, pp. 890-894, 2012.

[14] T. Rutherford, Z. Wang, X. Shu, B. Huang, and D. Clarke, "Laboratory investigation into mechanical properties of cement emulsified asphalt mortar," Construction and Building Materials, vol. 65, pp. 76-83, 2014.

[15] R.-S. Yang, K.-F. Liu, J.-J. Ren, D. Liu, and X.-Y. Liu, "Research on effect of cement asphalt mortar damages on dynamic characteristics of wheel-rail system," Journal of the China Railway Society, vol. 36, no. 7, pp. 79-84, 2014 (Chinese).

[16] K. Popp, I. Kaiser, and H. Kruse, "System dynamics of railway vehicles and track," Archive of Applied Mechanics, vol. 72, no. 1112, pp. 949-961, 2003.

[17] W. Zhai, K. Wang, and C. Cai, "Fundamentals of vehicle-track coupled dynamics," Vehicle System Dynamics, vol. 47, no. 11, pp. 1349-1376, 2009.

[18] Z. He and X. Yang, "Dynamic response analysis of an asymmetric coupled vehicle-track system generated by voided elastic two-block sleeper," Shock and Vibration, vol. 2016, Article ID 4985265, 11 pages, 2016.

[19] H. Claus and W. Schiehlen, "Dynamic stability and random vibrations of rigid and elastic wheelsets," Nonlinear Dynamics, vol. 36, no. 2-4, pp. 299-311, 2004.

[20] S.-T. Yen and Y.-H. Lee, "Parameter identification and analysis of a slab track system using 3D ABAQUS program," Journal of Transportation Engineering, vol. 133, no. 5, pp. 288-297, 2007.
[21] Z. Luo, W.-M. Zhai, C.-B. Cai, and K.-Y. Wang, "Dynamics model of slab track subjected to moving vehicle and its verification," Journal of the China Railway Society, vol. 32, no. 4, pp. 70-73, 2010 (Chinese).

[22] J. Blanco-Lorenzo, J. Santamaria, E. G. Vadillo, and O. Oyarzabal, "Dynamic comparison of different types of slab track and ballasted track using a flexible track model," Proceedings of the Institution of Mechanical Engineers, Part F: Journal of Rail and Rapid Transit, vol. 225, no. 6, pp. 574-592, 2011.

[23] W. Zhai, Vehicle-Track Coupled Dynamics, China Science Publishing, Beijing, China, 2015 (Chinese).

[24] K. Liu, Research on Cement Asphalt Mortar Damage and Maintenance Standards for Frame Type of Slab Track, Southwest Jiaotong University, Chengdu, China, 2013 (Chinese). 


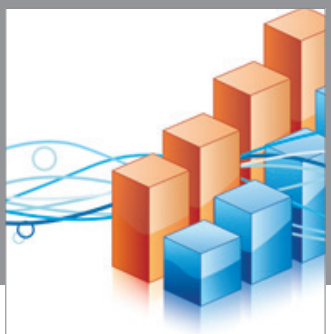

Advances in

Operations Research

vatem alat4

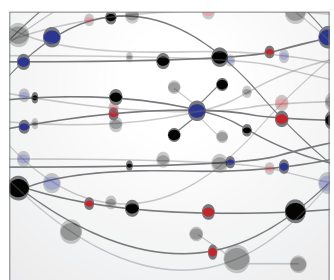

\section{The Scientific} World Journal
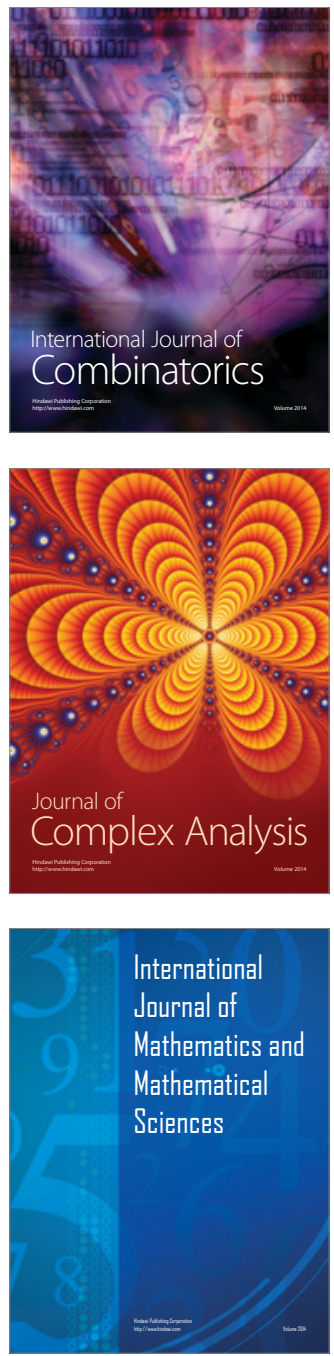
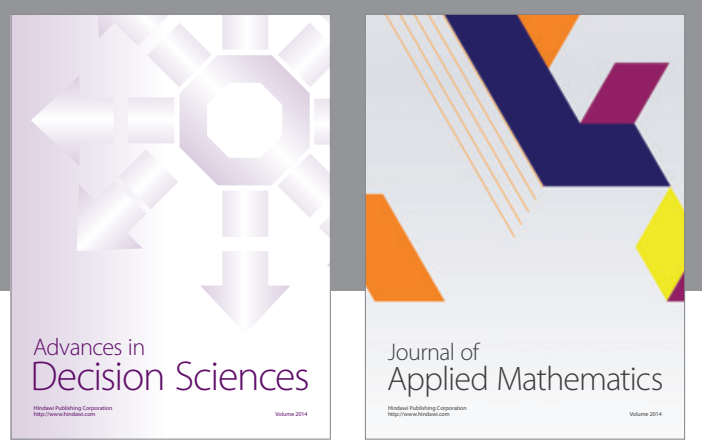

Algebra

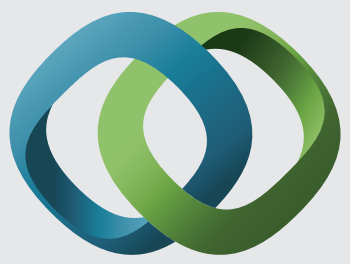

\section{Hindawi}

Submit your manuscripts at

http://www.hindawi.com
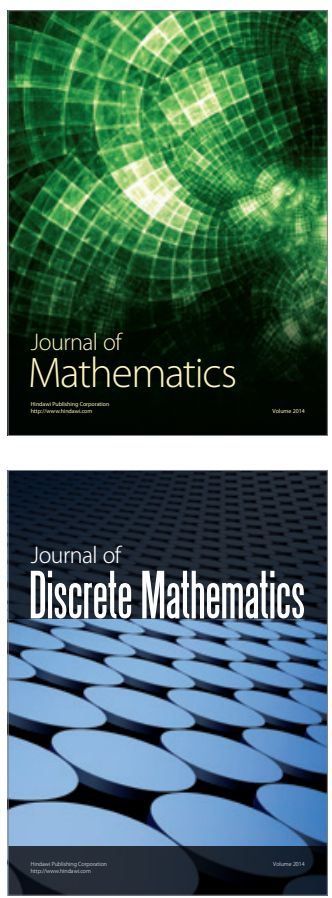

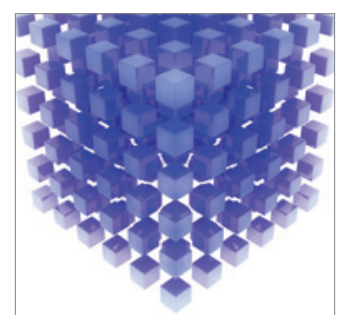

Mathematical Problems in Engineering
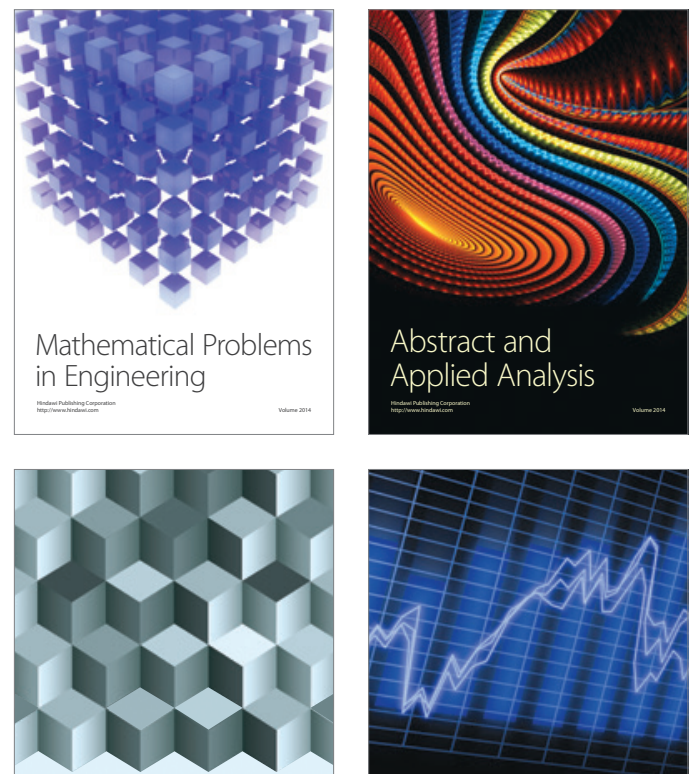

Journal of

Function Spaces

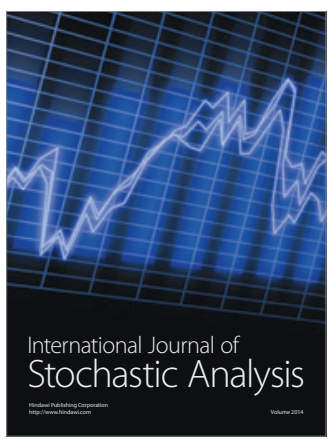

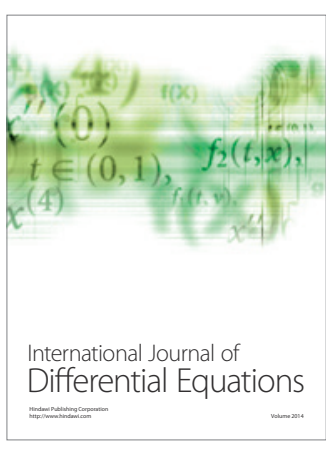
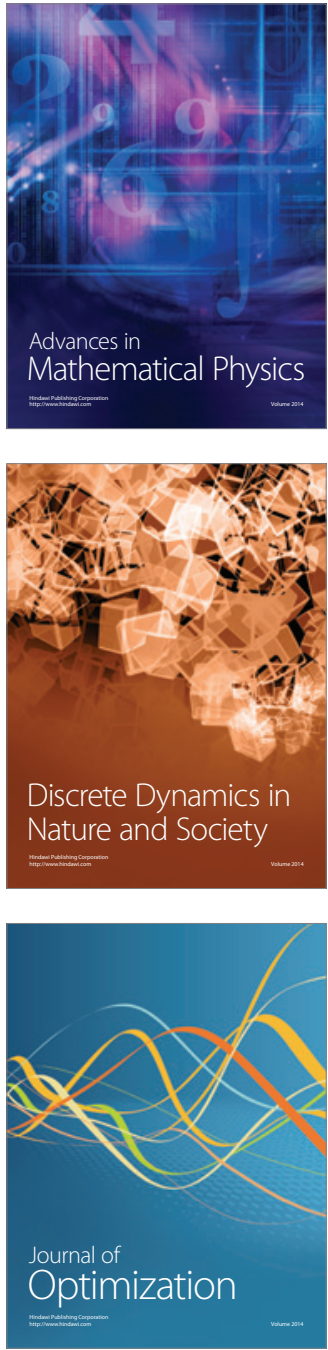